\title{
Relevant Research on Competency in Sports Field*
}

\author{
Shaocong Zhao \\ Sports Department \\ Xiamen University of Technology \\ Xiamen, China 361024
}

\begin{abstract}
Based on literature review method and through analysis of 150 related papers published, the author finds that domestic research on competency in sports field has the following problems: lack of standardization and diversity in adopting research methods; lack of unified standards for determining performance indicators and for determination methods; too much repetitive research due to overly concentrated research objects; narrow regional scope of sample selection, etc., and predicts the developing trend of future research.
\end{abstract}

\section{Keywords - competency; sports field; literature review}

\section{INTRODUCTION}

In 1911, when the father of management science Taylor realized the difference between excellent workers and inferior ones in finishing their work, he advised the manager to define the elements of workers' competency. In 1973, MeClelland, an American psychologist, for the first time put forward the concept of competency which was soon applied in every field and became a research hot spot of scholars in every field. In consideration of the role played by competency in very field, China management and psychological fields started to conduct research in competency since 1980s, and have made fruitful achievements. Although research in competency in sports field was started relatively late in China, it has been developing fast, and pertinent literature on competency in sports field shows a growth spurt. At present, there are 150 related papers available and published in recent ten years. To understand the current situation of research on competency in sports field, this paper straightens out the existing literature, analyzes the existing problems in current research in addition to exploring the developing trend of competency in sports field.

\section{CHARACTERISTICS OF CURRENT RESEARCH ON COMPETENCY IN SPORTS FIELD}

\section{A. Research Objects}

Domestic researchers in sports field mainly focus on the following research objects: 1 . Research on competency of PE teachers, such as Research on Competency of PE teachers in

*Fund project

1: PXM2017-014206-000006 Construction of scientific and technological service capacity- improvement of scientific research level "Research on characteristics and competency of Beijing fitness group leader". 2: PXM2017_014206_000014 Construction of scientific and technological service capacity--promotion plan project "Study of current situation of physical fitness organization, participation and needs of Beijing civilians".
Colleges and Universities (Qiu Fen, 2015) [1], Competence Modeling and Empirical Study on Competence of PE Teachers of Secondary School (Zhang Changcheng, 2011) [2], Survey Research on Competency of PE Teacher of Middle School (Pan Gaofeng, 2008), A Study of the Construction of a Physical Education Teacher Competency Model (Lu Sanmei, Zhu Shiyan, 2012) [4], etc.; 2. Research on competency of sports coach, such as, Study on the Issues about Competency of Competitive Sport Coach (Ji Chengshu, 2010) [5], Research on Relationship between the Competency Model of Chinese Athletic Coach and Coach's Performance (Yin Bichang, 2014) [6], Study on Competent Model of Professional Sports Coaches in China (Liu Liu, Wang Bin, 2017) [7], Research on the Competency Model and Scale Constructing and Competency Measurement of Professional Coaches in China (Qiu Fen, Yao Jiaxin, 2009) [8], Relationship Between Job Characteristics and Competence of Professional Basketball Coaches in China (Jia Lijuan, Wu Kun, 2013) [9], etc.; 3. Research on other aspects such as: Competency Model of Sports News Professionals and Training Method (Wang Kai, 2013) [10], Research on Competence of the Managers of Sports Fitness Club (Zheng Rui, 2008) [11], Study on Competence of Top Executives in China's Sports Enterprises (Jia Peng, Yao Jiaxin, 2006) [12], On Features of Competency of Talents in Sports Industry and Establishing of Its Training Mode (Lang Qiang, Zhao Wei, 2009) [13] etc. In overseas sports field, the main research objects are sport organization managers (Case \& Branch, 2003) [14], sport event managers (Peng, 2001) [15], sport managers in sport clubs and sport federations, (Horch \& Schuette, 2003 ) [16] etc. By consulting related literature on research on competency in sports field, the author found that almost all domestic and overseas scholars focus on the research objects-- PE teachers and sports coaches, which causing serious repetitive study. Comparatively speaking, overseas research on competency in sports fields started earlier and covers wider range of research objects.

\section{B. Research Methods}

Main research methods in competency modeling include: Behavioral Event Interview, Critical Incidents Technique, Questionnaire Method, Focused Interview, Expert Group Opinion Method, Job Analysis Method, Situational Judgement Test, Group Multilevel Performance Examination, etc. The mostly adopted method in studying competency in sports field is Behavioral Event Interview. For example, Qiu Fen (2008) employed Behavioral Event Interview to build a competency model of professional coaches in China[17]; Lu Sanmei (2012) also used this method to construct physical education teacher 
competency model[4] etc. Using Critical Incident Interview to build model includes: based on Critical Incident Interview, Yin Bichang (2014) interviewed 12 excellent athletic coaches and established competency model of Chinese athletic coach[6]; Jia Peng and Yao Jiaxin (2006) also used this method to obtain the elements of competency of top executives in China's sports enterprises[12], etc. Using other methods to conduct research on competency includes: for example, based on literature and questionnaire method, Zhang Changcheng (2011) proposed that characteristics of competence of PE teachers in secondary school are composed of three dimensions: comprehensive ability characteristics, personality characteristics and necessary knowledge[2]. By reference to competency research achievements of Zhang Changcheng and other scholars, Tang Xiaohua (2014) made improvement of measuring questions, semantic expressions, logical relations, etc. of the scale, and conducted research on competence of female PE teachers [18]. Tian Guang et.al (2014) used the principle of Fuzzy Math and Analytic Hierarchy Process to construct a evaluation system of $\mathrm{PE}$ teachers of colleges and universities[19]. Zhang Jie, Lv Mozhu (2014) applied Delphi Method and Behavioral Event Interview to build a physical training management competency mode of professional Wushu form coaches, etc[20]. In the field of management, it is more common to use Behavioral Event Interview, Questionnaire Method, Focused Interview, and other methods in combination. However, in China, scholars in the sports filed are likely to use a single method to conduct the research on competency, that is, they commonly adopts the Behavioral Event Interview to build competency model. Moreover, some scholars, for the sake of convenience, often directly adopt others' research scale just through slight modification, even for the research object not exactly the same. Considering the scientificity of research and accuracy of modeling, it is advisable to select appropriate research methods according to the research objects, for example, it is more reasonable to combine Behavioral Event Interview, Questionnaire Method and other methods to build competency model.

\section{Research Content}

\section{1) Competency modeling is the mainstream research}

According to Qiu Fen's doctoral thesis (2008), she conducted behavioral event interviews with 34 professional sports coaches and constructed a competency model of professional coaches in China. The model has been applied by many scholars in the research of competency of coaches [17]. Based on Literature Research Method and Questionnaire Method, Zhang Changcheng (2011) built a competency model of PE teachers of secondary school [2]. Based on Questionnaire Method, Wang Jingwei constructed a competency model of sports agent [21]. Forkken (2004) constructed a competency model of US national park and recreation board member [22], etc. The scholars constructed different competency models of different roles, and we can see that there are differences in competency of different roles, and these competency models constructed have important value as references for others studying competency.

\section{2) Difference of competency level and its application}

The research of competency differences mainly involves the relationship between the competency level and people of different level, sex, professional title, education background, etc. According to research, Yin Bichang (2014) found that there is difference of competency of Chinese athletics coaches in different dimensions of the competency model [2]. Tang Xiaohua (2014) held that competency of female PE teacher in middle school are related to the region and educational background structure of the school the teacher is in, but not there is no significant difference between their competency and professional title[18]. Through research, Judd (1995) deemed that there is a difference in the competencies between male and female administrators [23]. Through research, Qiu Fen (2015) held teachers of different professional titles and ages are different in five dimensions including knowledge repertory and learning, organization and management, professional promotion and development, communication and cooperation, and scientific research innovation [1]. Wang Kai (2013) constructed a competency model of sports news professionals, and put forward that the model can be used as a reference in the training of sports news professionals [10]. Kyungro and Young (2003) built a competency model of fitness club instructors and suggested that the research model can be used as research basis in the training and education of fitness professionals [24]. Domestic researchers in sports field conducted research of PE teachers, coaches, sports administrators in colleges and universities, etc., and constructed corresponding competency models which provide basis for the recruitment, training and performance assessment, etc. of PE teachers, coaches and sports administrators in colleges and universities.

\section{PROBLEMS EXISTING IN THE RESEARCH OF COMPETENCY IN SPORTS FIELD}

In the 1980s, our scholars began to study competency, and their theoretical content and research achievements have also been widely approved by the academic community and the industry. With the cross infiltration of management, psychology and other disciplines, competency theory has already become a hot topic in the field of sports research. Its research perspective, research methods and research objects have become the focus of sports researchers. In the last ten years, the research on competency in the sports field has developed rapidly and has achieved certain results. However, due to the late start, there is still a certain gap when it is compared to overseas studies, other management studies and psychology disciplines. The current problems existing in the research of competency in sports field in China include:

\section{A. The Research Method Is Not Standardized and the Method Applied Is Single}

a. To achieve the competency character indicators is a critical step in constructing the competency model. Obtaining the indicators with a scientific method directly affects the accuracy of the model construction. The scholars from sports field can obtain these indicators by using the behavioral event interview method (BEI), critical incidents technique method (CIT), questionnaire survey, Delphi method, Pareto analysis method, 360-degree feedback method and other methods. 
Conducting interviews with subjects in critical incidents plays an important role in identifying specific competency elements, structure, content, and hierarchical behaviors. Therefore, behavioral event interview is currently recognized as the most effective modeling method for competency [25]. However, the process of compiling a competency code dictionary for behavioral event interview technique is complex. It is difficult to control the errors, and the coding technology requirements are high. Some scholars, to facilitate the research, compile the scale directly with the indicators obtained from the existing documents and by subjective scoring of relevant experts. Some scholars even directly use the scales of a different subject by other scholars to compile their competency assessment scales through subjective improvement. This is clearly not standardized. b. In obtaining the competency indicators, indepth interviews with subjects in critical events are usually added to the projective techniques such as the theme apperception. In this way, the competency character indicators can be more comprehensively and accurately excavated. The competency indicators obtained through the questionnaire method, for most of the time, the interviewees consider that it "should be", but in reality they do not necessarily use it. Therefore, it is incomplete to use the questionnaire method to obtain the competency indicators. The competency test scale compiled is not rigorous enough. c. The research methods are confusing, and the critical incidents technique (CIT) is a research technique of human resource management proposed by Flanagan in 1949. The behavioral event interview (BEI) is an operational interview technique developed by McClelland and Dailey (1974) in combination with the critical event method (CIT) and theme apperception test (TAT). The two methods are similar but different. Unfortunately, many scholars have confused behavioral event interview (BEI) and critical incidents technique (CIT) as a research method. The behavioral event interview method requires finding the competency indicators by investigating the differences between the excellent performance groups and the ordinary performance groups in dealing with critical events. There are also differences in data processing. Some scholars do not distinguish whether the performance of the investigated subjects is excellent before the use of behavioral event interviews to obtain competency indicators, which is clearly non-standard. d. The acquisition method is single. Scholars often use one research method to obtain the competency factors, and fewer scholars use comprehensive research methods in their study. The sample size of the questionnaire interview is too small. For the stability of the results, the questionnaire on the validity test of the competence list usually requires that the number of interviewees should be 5-10 times the number of the answer items. However, many scholars did not investigate according to this requirement.

\section{B. There Is No Unified Standard for Performance Indicators and Determination Methods.}

Scholars often use behavioral event interviews to research on competency, but this method needs to differentiate the performance of the subjects in advance. However, scholars do not have a unified assessment method for performance due to the difference of research subjects, and there is not a relatively objective standard, e. g. in determining the performance of PE teachers, some scholars use the number of working years, the number of teachers, and school-level awards; in judging the performance of coaches, they use grades, provision of talents, etc. All these indicators are based on the subjective judgment of researchers, and lack of scientific confirmation, which will affect the accuracy of the research results. I believe such method is comparatively scientific for determining the performance as: the performance evaluation system for track coaches in China established by a scholar of Zhang Yunliang. The method uses key performance indicators (KPI Performance indicators, KPl) to evaluate the performance of track and field coaches [26], namely: coach's key performance $=$ achievement of athletes $\times$ achievement weight + title $\times$ title weight + selection (provision) number of athletes $\times$ sports selection weight (the sum of the achievement weight, title weight and sports selection weight is $100 \%$ ).

\section{The Subjects Are Too Concentrated, and There Are Too Many Repetitive Researches, and the Selection Area of Samples Is Too Narrow}

The objects of research of competency in the sports field are too concentrated, among which PE teachers and coaches are the most. According to the incomplete statistics, the research on the competency of PE teachers and coaches accounts for more than $60 \%$ of the total researches in the sports field. Therefore, due to the excessive concentration of research objects, repetitive research phenomenon will inevitably occur, for example, a lot of scholars are constructing competency models for PE teachers. The geographical scope of the sample selection is too narrow, e.g. some scholars take the PE teachers of few schools in a city or county as the research objects, the competency model constructed for PE teachers obviously does not represent all teachers, and this selection method of samples will affect the reliability and unity of the results.

\section{PROSPECt ReSEARCH OF COMPETENCY IN SPORTS FIELD}

\section{A. The Scientificity of Research Methods Needs Further Specification}

In the research method of competency model, scholars choose their methods according to their own situation, as for which method is suitable to build which type of competency model and how to make choices; they have formed a unified standard. The use of research methods in the sports field is relatively single. The combination of multiple research methods is rarely used. In order to improve the comprehensiveness of data collection, this method should be used. At present, scholars have few researches on research methods, which need to be further studied.

\section{B. The Unity and Rationality of Performance Assessment Need Further Study}

Competency is constructed basing on the hypothesis that it could effectively predict performance. However, there are few empirical researches on the relationship between competency and performance in the sports field. Most scholars' judgment criteria for performance tend to be subjective, and there is no 
objective standard for the judgment. The performance judgments of different research subjects have their own characteristics, which makes it difficult to make objective judgments. Therefore, how to find scientific method for performance judgment in line with research objects is the direction that competency scholars should study in future.

\section{The Scope of Research Objects and Sample Selection Needs Further Expansion}

The scope of research object groups in competency research is too narrow. For example, the research on the competency of the head of the physical fitness team is still vacant. In the future, the scope of research should be expanded to fit the increased number of researches on different subjects and reduce the repetitiveness. The scope of the sample of the questionnaire should be appropriately expanded to improve the reliability and uniformity of the research results.

\section{CONCLUSION}

The competency research in sports field started late but developed fast. Currently, there are problems such as nonstandard use of research methods, inconsistent performance evaluation criteria, more research on repetitive objects, and narrow sample selection area. In the future, we must standardize research methods, enrich research objects, expand sample selection during the research process, unify the assessment standard of performance and perfect scientific research of competency in the field of sports to promote the competency research in sports field to a new level.

\section{REFERENCES}

[1] Qiu Fen Research on Competency of PE teachers in Colleges and Universities [M]. Wuhan University Press, 2015: 12-13.

[2] Zhang Changcheng Competence Modeling and Empirical Study on Competence of PE Teachers of Secondary School [D]. PhD Thesis of Fujian Normal University, 2011

[3] Pan Gaofeng Survey Research on Competency of PE Teacher of Middle School [D]. Master's Thesis of Central China Normal University, 2008.

[4] Lu Sanmei, Zhu Shiyan A Study of the Construction of a Physical Education Teacher Competency Model [J]. Journal of Physical Education, 2012, 19 (2) : 83-87.

[5] Ji Chengshu Research on Competency of Sports Coach [D]. Master's Thesis of Tianjin University, 2010: 64-65.

[6] Yin Bichang Research on Relationship between the Competency Model of Chinese Athletic Coach and Coach's Performance [J]. China Sport Science, 2014,34 (6) : 59-67

[7] Liu Liu, Wang Bin Study on Competent Model of Professional Sports Coaches in China [J]. China Sport Science, 2017, 27 (3) : 3-11.

[8] Qiu Fen, Yao Jiaxin Research on the Competency Model and Scale Constructing and Competency Measurement of Professional Coaches in China [J]. China Sport Science, 2009, 29 (4) : 17-26

[9] Jia Lijuan, Wu Kun Relationship Between Job Characteristics and Competence of Professional Basketball Coaches in China [J]. Journal of Wuhan Institute of Physical Education, 2013, 47 (4) : 46-47.

[10] Wang Kai Competency Model of Sports News Professionals and Training Method [J]. China Sport Science, 2013, 49 (4) : 132-138

[11] Zheng Rui Research on Competence of the Managers of Sports Fitness Club [D]. Master's Thesis of Yangzhou University, 2008
[12] Jia Peng, Yao Jiaxin Study on Competence of Top Executives in China's Sports Enterprises [J]. Wuhan Institute of Physical Education , 2006, 40 (7) : 37-40.

[13] Lang Qiang, Zhao Wei On Features of Competency of Talents in Sports Industry and Establishing of Its Training Mode [J]. Journal of Capital Institute of Physical Education, 2009, 21 (1) : 43-45

[14] Case, R.., Branch, J.D.. A study to examine the job competencies of sport facility managers. International Sports Journal, Summer 2003:7(2).P.25-38,14P.

[15] Peng, H..Competencies of sport event managers in the United States Eugene, OR:Microform Publications, University of Oregon. 2001.

[16] Horch, H.D.,Schuette, N.. Competencies of sport managers in German sport clubs and sport federations[J]. London: Managing leisure, 2003, 8 (2): 70-84.

[17] Qiufen Competency Model Construction and Measurement of Professional Coaches in China [D]. PhD Thesis of Beijing Sport University, 2008.

[18] Tnag Xiaohua Theoretical and Empirical Study on the Competency of Female PE Teachers in Middle Schools [D]. Master's Thesis of Fujian Normal University, 2014

[19] Tian Guang, Gaoxu etc. Construction of Evaluation Index System for Competency of College PE Teachers in Guizhou Province [J]. Sports Research and Education, 2014, 29 (4): 36-38.

[20] Zhang Jie, Lu Mozhu. Study on the Competency Structure of Physical Training of Wushu Coaches[J]. Journal of Shenyang Sport University, 2014, 33 (6): 123-134.

[21] Wang Jingwei. Research on Competency Model Construction and Evaluation of Sports Brokers [D]. Master's Thesis of Ningbo University, 2010.

[22] Fokken, P.M.. Construction and validation for competencies of aboard self-assessment a questionnaire (BSAQ) for park and recreation board members : a model development[J].Eugene, OR: Kinesiology Publications, University of Oregon. 2004:128-133.

[23] Judd, M.R.. A gender comparison of competencies important for success in college athletic administration. Physical Educator, winter 1995: 52 (1), p8-13.

[24] Kyungro C ., Young K. K. Competencies for Fitness Club Instructors: Results of a Delphi-study. International Journal of Applied Sports Sciences, 2003, 15 (1):56

[25] Spencer Jr. L M, Spencer S M. (1993) Competence at wor k: Models for superior performance. New York: John Wiley\&Sons, Inc.

[26] Yun Liang. Research on Professional Labor Characteristics and Performance Evaluation of Track and Field Coaches in China [D]. PhD Thesis of Beijing Sport University, 2010. 